\title{
HASIL BELAJAR FISIKA DITINJAU DARI KECERDASAN EMOSIONAL SISWA SMA NEGERI 2 SEKAMPUNG
}

\author{
Ayang Kinasih \\ Sains dan Teknologi, Universitas Nahdlatul Ulama Lampung, ayang kinasih@unulampung.ac.id
}

\section{INFO ARTIKEL}

Riwayat Artikel:

Diterima: 07-04-2018

Disetujui: 20-04-2018

\section{Kata Kunci:}

Hasil Belajar

Kecerdasan Emosional

\section{A. LATAR BELAKANG}

Pendidikan merupakan hak asasi manusia yang paling mendasar dan bersifat universal, di Indonesia kesempatan untuk memperoleh pendidikan di jamin dalam Undang-Undang No. 20/2003 tentang sistem pendidikan nasional menjelaskan bahwa: "Pendidikan nasional adalah pendidikan yang berdasarkan pancasila dan Undang-Undang Dasar Negara Republik Indonesia 1945, yang berakar pada nilai-nilai agama, kebudayaan nasional Indonesia, dan tanggap terhadap tuntutan perubahan zaman".

Belajar merupakan suatu proses dari seorang individu yang berupaya mencapai tujuan belajar yang biasa disebut hasil belajar, yaitu suatu bentuk perubahan perilaku yang relatif menetap [3]. Kegiatan belajar mengajar pada hakekatnya merupakan serangkaian kegiatan pendidikan yang bertujuan untuk mendewasakan anak didik, dan mempersiapkan mereka agar mampu menghadapi masa depan yang lebih kompleks. Mendewasakan anak didik mengandung beberapa unsur tujuan seperti kecerdasan, kepribadian luhur memiliki keterampilan, berpengetahuan luas dan sebagainya. Beberapa unsur tujuan ini dapat tercermin dalam output belajar anak, berupa hasil belajar.

Goleman memperluas kemampuan kecerdasan emosional menjadi lima subvariabel utama, yaitu sebagai berikut: 
a. Kesadaran diri: mengetahui apa yang kita rasakan pada suatu saat dan menggunakannya untuk memandu penembalian keputusan diri sendiri, memiliki tolak ukur yang realitas atas kemampuan diri dan kepercayaan diri yang kuat.

b. Pengaturan diri: mengenai emosi sedemikian rupa sehingga berdampak positif kepada pelaksanaan tugas, peka terhadap kata hati dan sanggup menunda kenikmatan sebelum tercapainya satu gagasan, maupun pulih kembali dari tekanan emosi.

c. Motivasi: menggunakan hasrat yang paling dalam untuk menggerakkan dan menuntut kita menuju sasaran, membantu kita mengambil inisiatif dan bertindak sangat efektif, serta untuk bertahan menghadapi kegagalan dan frustasi. Mengambil inisiatif dan bertindak sangat efektif, serta untuk bertahan menghadapi kegagalan dan frustasi.

d. Empati: merasakan yang dirasakan oleh orang lain, mampu memahami perspektif mereka, menumbuhkan hubungan saling percaya dan menyelaraskan diri dengan bermacam-macam orang.

e. Keterampilan sosial: menangani emosi dengan baik ketika berhubungan dengan orang lain dan dengan cermat membaca situasi dan jaringan sosial, berinteraksi dengan lancar, menggunakan kemampuan ini untuk memengaruhi dan memimpin, bermusyawarah dan menyelesaikan perselisihan dan untuk bekerja sama dan bekerja dalam tim [5].

Kecerdasan emosional adalah faktor penting yang sangat berpengaruh terhadap hasil belajar siswa selain faktor-faktor yang ada, karena kecerdasan emosional dalam pertumbuhan dan perkembangan sangat berperan untuk membentuk sikap kritis dan kreatif siswa. Kecerdasan emosional yang dimiliki oleh siswa akan menimbulkan hasil belajar yang maksimal.

Hal ini diperkuat oleh Agustian yang menyatakan, dari berbagai hasil penelitian, telah banyak terbukti bahwa kecerdasan emosional memiliki peranan yang jauh lebih penting dibandingkan kecerdasan intelegensi (IQ). Kecerdasan intelegensi (IQ) barulah sebatas syarat minimal meraih keberhasilan, namun kecerdasan emosional yang sesungguhnya (hampir semua terbukti) mengantarkan seseorang menuju puncak prestasi [2].

Berdasarkan latar belakang, maka dapat dikemukakan penelitian dengan judul: Analisis Hasil Belajar Fisika Ditinjau Dari Kecerdasan Emosional Siswa SMA Negeri 2 Sekampung Tahun Pelajaran 2017/2018.

\section{B. METODE PENELITIAN}

Jenis penelitian ini adalah deskriptif kualitatif yaitu penelitian yang dimaksudkan untuk mengumpulkan informasi mengenai status suatu gejala yang ada, yaitu keadaan gejala menurut apa adanya pada saat penelitian dilakukan. Sampel penelitian menggunakan proporsional random sampling jadi sampel yang diambil 20\% dari populasi atau sebesar 35 siswa. Penelitian ini menggunakan instrumen soal tes yang disusun berdasarkan materi yang telah diajarkan yaitu gerak lurus berubah beraturan (GLB) dan gerak lurus berubah beraturan (GLBB) untuk kelas X, dinamika rotasi untuk kelas XI, dan elektrostatika untuk kelas XII, sedangkan untuk mengukur kecerdasan emosional, peneliti menggunakan instrumen angket yang dikemukakan oleh Goleman dalam bentuk pilihan ganda dengan menyediakan lima alternatif jawaban [5]. Untuk memperoleh hasil pengukuran data yang valid dan relibel maka dilakukan uji ahli dan uji lapangan terlebih dahulu untuk mengetahui tingkat validitas dan reliabilitas alat ukur. Setelah data yang diperlukan terkumpul melalui metode tes dan kuesioner kemudian data tersebut dianalisis.

\section{HASIL DAN PEMBAHASAN}

\section{Tingkat keberhasilan hasil belajar fisika} ditinjau dari kecerdasan emosional

TABEL 1

TINGKAT KEBERHASILAN BELAJAR FISIKA DITINJAU DARI KECERDASAN EMOSIONAL

\begin{tabular}{cccc}
\hline Hasil Belajar & \multicolumn{3}{c}{ Kecerdasan Emosional } \\
Fisika & $\mathrm{T}$ & $\mathrm{S}$ & $\mathrm{R}$ \\
\hline $\mathrm{T}$ & 12 & - & - \\
$\mathrm{S}$ & 2 & 14 & 1 \\
$\mathrm{R}$ & - & 2 & 4 \\
\hline
\end{tabular}

Pada tabel 1 dapat dilihat bahwa siswa yang memiliki kecerdasan emosional tinggi dan memperoleh keberhasilan belajar fisika sebanyak 12 siswa, dimana 3 siswa kelas X, 4 siswa kelas XII, dan 5 siswa kelas XII. Hal ini menunjukan bahwa siswa yang memiliki kecerdasan emosional tinggi maka tingkat keberhasilan belajar fisika akan semakin besar. Artinya, hasil penelitian menunjukan kecenderungan hasil belajar yang diperoleh siswa sama dengan tingkat emosionalnya.

Menurut hasil penelitian Jacobs dan Chen, para peneliti di Hay/Mc Ber London berkesimpulan bahwa:

Kemampuan kognitif murni adalah sebesar $27 \%$ lebih sering ditemukan pada bintang kinerja dibandingkan pada orang biasa, sedangkan keunggulan dalam kecakapan emosi mencapai 53\% lebih sering. Dengan kata lain, kecakapan emosi dua kali lebih berperan dalam menjadikan seseorang berprestasi tinggi, dibandingkan kepandaian murni dan keahlian teknis [1].

\section{Kontribusi kecerdasan emosional terhadap hasil belajar fisika}


TABEL 2

\section{DAFTAR KONTINGENSI HASIL BELAJAR DAN KECERDASAN EMOSIONAL FISIKA}

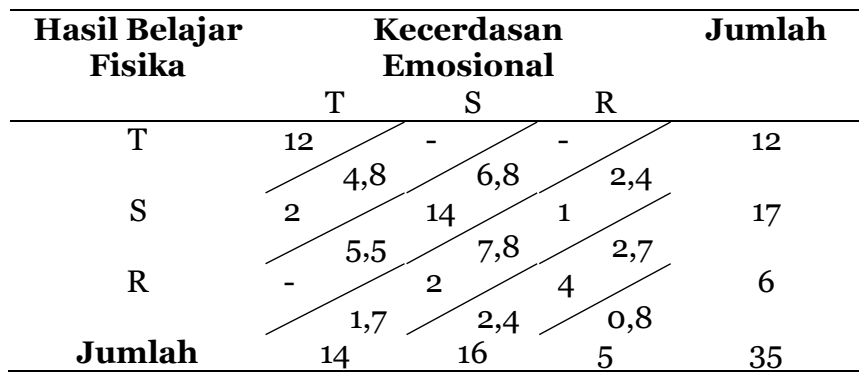

Berdasarkan tabel 2 menggunakan rumus statistik dapat diperoleh nilai $\chi^{2}=41,34$. Dengan $\alpha=0,01$ dan $\mathrm{dk}=(3-1)(3-1)=6$, didapat $\chi^{{ }^{2}{ }_{0,99}=13,3 .} \quad \chi^{2}(1-\alpha)(\mathrm{B}-$ $1)(\mathrm{K}-1)<\quad \chi \quad{ }^{2}, \quad(13,3<41,34) . \quad$ Jadi penelitian memberikan pengujian yang sangat berarti. Sehingga dapat disimpulkan bahwa ada hubungan sangat nyata antara kecerdasan emosional siswa dengan hasil belajar fisika. Derajat hubungan antara kecerdasan emosional siswa dengan hasil belajar fisika diperoleh menggunakan koofesien kontingensi $\mathrm{C}=0,735$ dan koofesien kontingensi maximum $\mathrm{C}_{\max }=0,816$.

Makin dekat harga $\mathrm{C}$ kepada $\mathrm{C}_{\max }$ makin besar derajat asosiasi antara faktor. Dengan kata lain, faktor yang satu makin berkaitan dengan faktor lain [4]. Membandingkan $\mathrm{C}=0,735$ dengan $\mathrm{C}_{\max }=0,816$ nampak bahwa derajat hubungan antara kecerdasan emosional dengan hasil belajar fiska sangat besar.

\section{Kesesuaian Hasil Belajar Fisika dengan Kecerdasan Emosional}

Berdasarkan tabel 1 dapat diketahui kesesuaian antara kategori hasil belajar fisika dengan kecerdasan emosional. terlihat pada grafik 1.

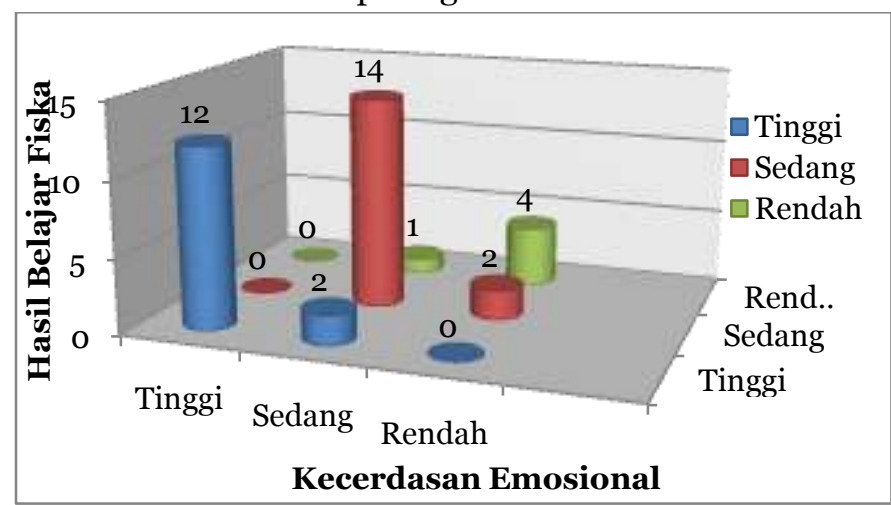

Gambar 1. Grafik kesesesuaian hasil belajar dengan kecerdasan emosional

Tabel 1 menunjukkan bahwa siswa yang memiliki kecerdasan emosional tinggi memperoleh hasil belajar tinggi sebanyak 12 siswa, atau sebesar 34,29\% dari jumlah sampel. Siswa yang memiliki kecerdasan emosional tinggi memperoleh hasil belajar sedang sebanyak 2 siswa, atau sebesar 5,71\% dari jumlah sampel.
Siswa yang memiliki kecerdasan emosional sedang memperoleh hasil belajar sedang sebanyak 14 siswa, atau sebesar $40 \%$ dari jumlah sampel. Siswa yang memiliki kecerdasan emosional sedang memperoleh hasil belajar rendah sebanyak 1 siswa, atau sebesar 2,86\% dari jumlah sampel. Siswa yang memiliki kecerdasan emosional rendah memperoleh hasil belajar sedang sebanyak 2 siswa, atau sebesar $5,71 \%$ dari jumlah sampel, dan siswa yang memiliki kecerdasan emosional rendah memiliki hasil belajar fisika rendah sebanyak 4 siswa, atau sebesar $11,43 \%$ dari jumlah sampel.

\section{Pola dukungan subvariabel kecerdasan emosional pada variasi kategori hasil belajar fisika siswa.}

TABEL 3

REKAPITULASI ANALISIS POLA DUKUNGAN SUBVARIABEL KECERDASAN EMOSIONAL DENGAN HASIL BELAJAR FISIKA DAN FREKUENSI KESESUAIAN HASIL BELAJAR FISIKA BERDASARKAN SUBVARIABEL KECERDASAN EMOSIONAL

\begin{tabular}{|c|c|c|c|c|c|}
\hline \multicolumn{3}{|c|}{$\begin{array}{l}\text { Kesesuaian Hasil Belajar } \\
\text { Fisika dan Kecerdasan } \\
\text { Emosional }\end{array}$} & \multirow{2}{*}{ Jumlah } & \multirow{2}{*}{$\begin{array}{l}\text { Jumlah } \\
\text { Total }\end{array}$} & \multirow{2}{*}{$\begin{array}{l}\text { NP } \\
(\%)\end{array}$} \\
\hline \multicolumn{2}{|c|}{$\begin{array}{c}\text { Subvariabel } \\
\text { Kecerdasan } \\
\text { Emosional }\end{array}$} & $\begin{array}{l}\text { Hasil } \\
\text { Belajar }\end{array}$ & & & \\
\hline \multirow{3}{*}{$\begin{array}{l}\text { Kesadaran } \\
\text { Diri }\end{array}$} & $\mathrm{T}$ & $\mathrm{T}$ & 11 & \multirow{3}{*}{27} & \multirow{3}{*}{$77,14 \%$} \\
\hline & $\mathrm{S}$ & $S$ & 12 & & \\
\hline & $\mathrm{R}$ & $\mathrm{R}$ & 4 & & \\
\hline \multirow{3}{*}{$\begin{array}{c}\text { Pengaturan } \\
\text { Diri }\end{array}$} & $\mathrm{T}$ & $T$ & 8 & \multirow{3}{*}{26} & \multirow{3}{*}{$74,28 \%$} \\
\hline & $\mathrm{S}$ & $\mathrm{S}$ & 12 & & \\
\hline & $\mathrm{R}$ & $\mathrm{R}$ & 6 & & \\
\hline \multirow{3}{*}{$\begin{array}{l}\text { Turut } \\
\text { Merasakan } \\
\text { (empati) }\end{array}$} & $\mathrm{T}$ & $\mathrm{T}$ & 10 & \multirow{3}{*}{30} & \multirow{3}{*}{$85,71 \%$} \\
\hline & $\mathrm{S}$ & $\mathrm{S}$ & 15 & & \\
\hline & $\mathrm{R}$ & $\mathrm{R}$ & 5 & & \\
\hline \multirow{3}{*}{$\begin{array}{l}\text { Keterampilan } \\
\text { Sosial }\end{array}$} & $\mathrm{T}$ & $\mathrm{T}$ & 8 & \multirow{3}{*}{28} & \multirow{3}{*}{$80,00 \%$} \\
\hline & $\mathrm{S}$ & $\mathrm{S}$ & 16 & & \\
\hline & $\mathrm{R}$ & $\mathrm{R}$ & 4 & & \\
\hline
\end{tabular}

Keterangan:

$$
\begin{array}{ll}
-\mathrm{T}=\text { Tinggi } & -\mathrm{S}=\text { Sedang } \\
-\mathrm{R}=\text { Rendah } & -\mathrm{NP}=\text { Nilai Persentase } \\
\mathrm{NP}=\frac{\text { jumla } h \text { total }}{\text { jumla } h \text { maksimal }} & \times 100 \% \\
\text {-Jumlah maksimal } & =35
\end{array}
$$

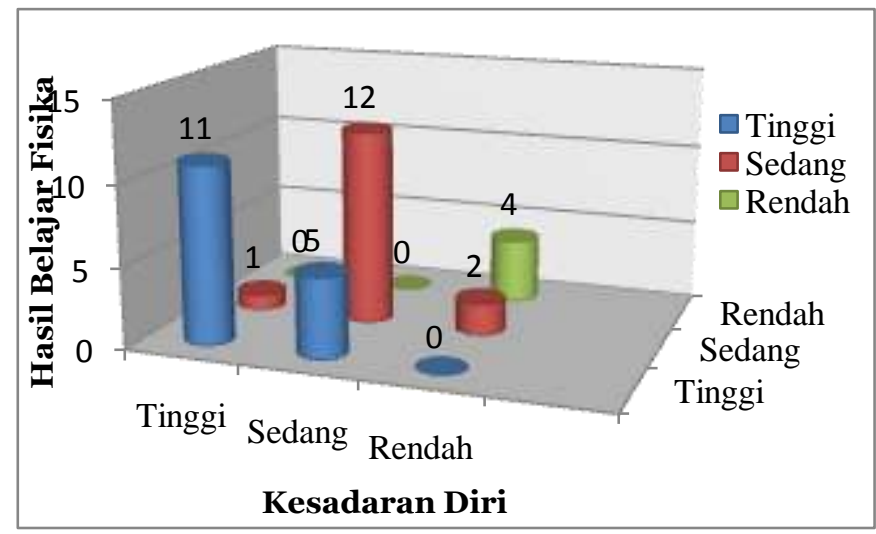

Gambar 2. Grafik hasil belajar fisika terhadap subvariabel kecerdasan emosional kesadaran diri. 


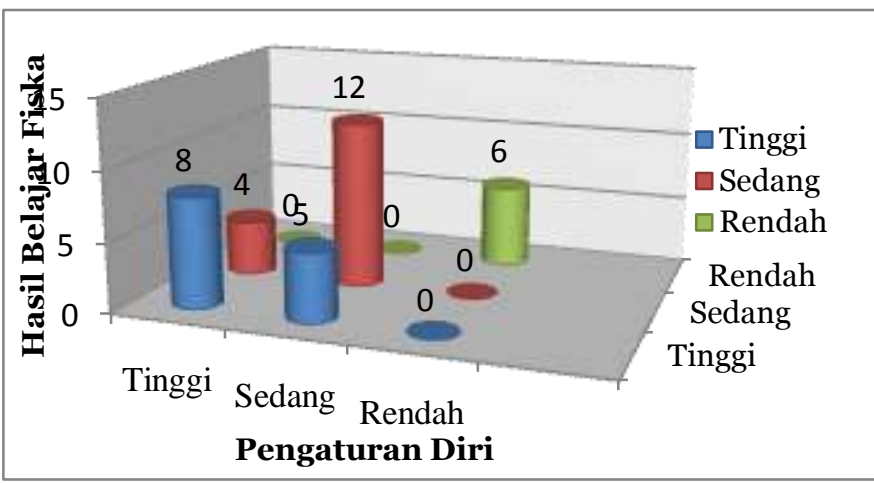

Gambar 3. Grafik hasil belajar fisika terhadap subvariabel kecerdasan emosional pengaturan diri.

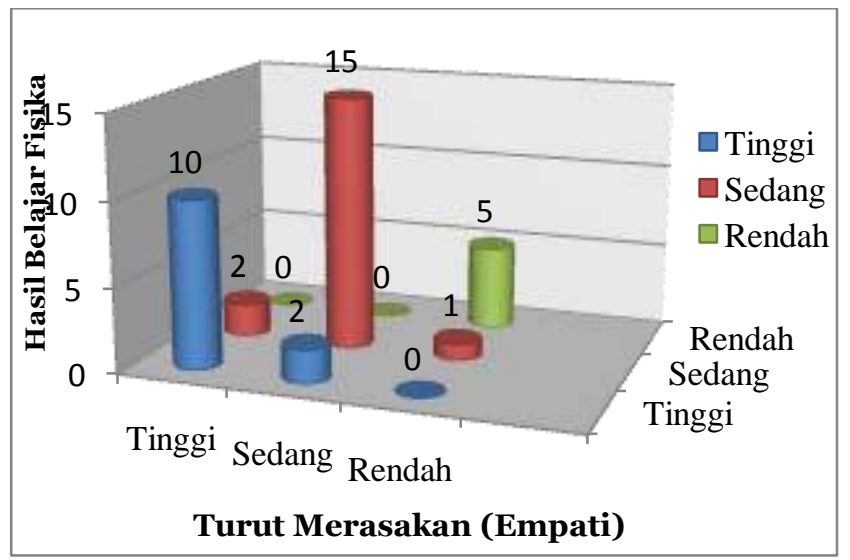

Gambar 4. Grafik hasil belajar fisika terhadap subvariabel kecerdasan emosional turut merasakan (empati).

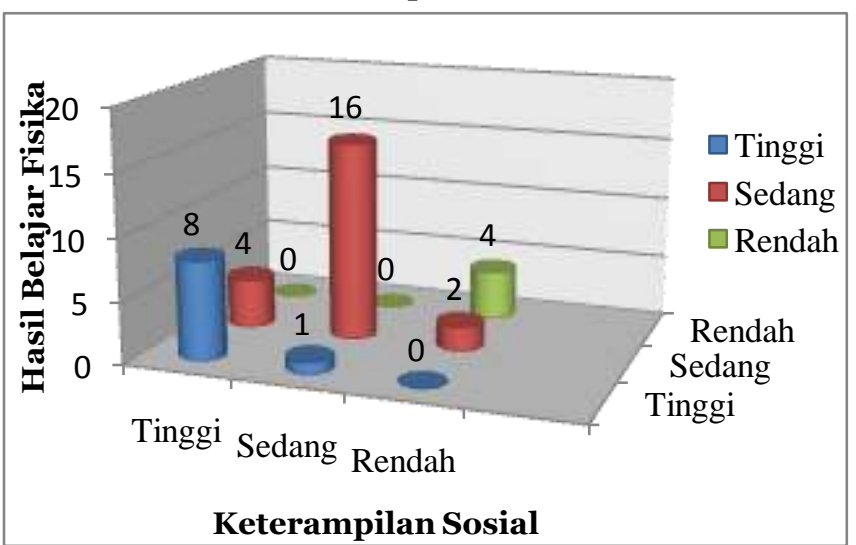

Gambar 5. Grafik hasil belajar fisika terhadap subvariabel kecerdasan emosional keterampilan sosial.

Berdasarkan tabel 3 terlihat bahwa hasil belajar fisika yang diperoleh siswa linear dengan kecerdasan emosional yang dimilikinya, artinya adalah siswa yang memperoleh hasil belajar fisika tinggi, dominan didukung oleh kesadaran diri, pengaturan diri, turut merasakan (empati), dan keterampilan sosial yang tinggi. Siswa yang memperoleh hasil belajar fisika sedang, dominan didukung oleh kesadaran diri, pengaturan diri, turut merasakan (empati), dan keterampilan sosial yang sedang. Siswa yang memperoleh hasil belajar fisika rendah, dominan didukung oleh kesadaran diri, pengaturan diri, turut merasakan (empati), dan keterampilan sosial yang rendah.

Dari data rekapitulasi analisis pola dukungan Subvariabel kecerdaasaan emosional dengan hasil belajar fisika siswa maka dapat diketahui subvariabel kecerdasan emosional yang dominan mendukung hasil belajar fisika (tinggi, sedang, dan rendah) yang diperoleh siswa. Subvariabel kecerdasan emosional yang dominan pada siswa yang memperoleh hasil belajar tinggi adalah kesadaran diri. Subvariabel kecerdasan emosional yang dominan pada siswa yang memperoleh hasil belajar sedang adalah keterampilan sosial dan subvariabel kecerdasan emosional yang dominan pada siswa yang memperoleh hasil belajar rendah adalah pengaturan diri. Sedangkan secara umum, subvariabel yang paling dominan terhadaap hasil belajar fisika adalah turut merasakan (empati).

\section{SIMPULAN DAN SARAN}

Berdasarkan pembahasan di atas dapat disimpulkan bahwa:

1. Siswa yang memiliki kecerdasan emosional tinggi maka tingkat keberhasilan belajar fisika paling besar,

2. kontribusi kecerdasan emosional siswa terhadap hasil belajar fisika sangat besar,

3. hasil belajar fisika sesuai dengan kecerdasan emosional siswa,

4. pola dukungan subvariabel kecerdasan emosional pada hasil belajar tinggi, yaitu siswa memiliki kesadaran diri, pengaturan diri, turut merasakan (empati), dan keterampilan sosial tinggi, pola dukungan subvariabel kecerdasan emosional pada hasil belajar sedang, yaitu siswa memiliki kesadaran diri, pengaturan diri, turut merasakan (empati), dan keterampilan sosial sedang, pola dukungan subvariabel kecerdasan emosional pada hasil belajar rendah, yaitu siswa memiliki kesadaran diri, pengaturan diri, turut merasakan (empati), dan keterampilan sosial rendah. Subvariabel kecerdasan emosional yang dominan mendukung hasil belajar adalah turut merasakan (empati).

Berdasarkan kesimpulan di atas dapat diketahui agar hasil belajar siswa meningkatan, maka kepada guru bidang studi fisika dapat memperhatikan aspek emosional siswa dalam proses pembelajaran, sehingga dapat merangsang siswa untuk belajar secara maksimal, serta dapat membantu perkembangan aspek-aspek kecerdasan emosional siswa seperti kesadaran diri, pengaturan diri turut merasakan (empati) dan keterampilan sosial, terutama turut merasakan (empati) karena turut merasakan (empati) lebih dominan mendukung hasil belajar fisika melalui pembelajaran yang lebih bervariasi.

Untuk siswa agar dapat mengalami peningkatan, maka kiranya siswa dapat mengelola emosinya secara maksimal dengan cara mengenali emosi diri, melepaskan emosi negatif, mengelola emosi diri sendiri, 
114 | JUSTEK, Vol. 1, No. 1, Mei 2018, hal. 110-114

memotivasi diri sendiri, mengenali emosi orang lain, mengelola emosi orang lain, dan memotivasi orang lain

\section{DAFTAR RUJUKAN}

[1] Agustian, Ary Ginanjar., Rahasia Sukses Membangun Kecerdasan Emosi dan Spiritual, Arga, Jakarta, 2001.

[2] Mudzhar, Ahmad., Hubungan Antara Kecerdasan Emosional Dan Intelektual Dengan Prestasi Belajar Siswa SMP Islam Jabung Malang, UIN, 2009.

[3] Mulyono, Abdurrahman., Pendidikan Bagi Anak Berkesulitan Belajar, Rineka Cipta, Jakarta, 2003

[4] Sudjana, Metode Statistika, Tarsito, Bandung, 1996.

[5] Uno B. Hamzah., Orientasi Baru Dalam Psikologi Pembelajaran, Bumi Aksara, Jakarta, 2008. 